\title{
Different profiles for the assessment of student theses in teacher education
}

\author{
Karin Stolpe ${ }^{1}$ (D) Lars Björklund $^{1}$ (D) $\cdot$ Mats Lundström ${ }^{2}$ (I) $\cdot$ Maria Åström $^{3}$
}

Accepted: 1 February 2021 / Published online: 31 March 2021

(c) The Author(s) 2021

\begin{abstract}
Previous research shows a discrepancy between different teachers' assessment of student theses. This might be an even larger problem in the context of teacher education, since teacher trainers originate from different disciplines. This study aims to investigate how different assessors prioritise between criteria for assessment. Criteria were elucidated using repertory grid interviews with teacher trainers. These criteria formed the basis for a webbased Qsort that was distributed to teacher trainers at three different universities. The 66 teacher trainers in this study represented different disciplines, but were all engaged in the supervision and examination of student theses from teacher education programmes. The analysis revealed three different factors, which have been labelled: logic text structure as product, research process as product and results as product. The differences may not be explained by the background (e.g. discipline, university or gender) of the teacher trainers. Together, these three factors explain why teachers assessing student theses may accentuate different personal criteria. Hence, this might impact on their grading practice and also the interrater reliability.
\end{abstract}

Keywords Assessment - Interrater reliability · Q methodology · Teacher education · Teachers' grading practice

\section{Introduction}

Student theses are widely used in higher education internationally. However, inconsistency in grading is common in complex higher education tasks, which in turn leaves students with a potential sense of unfairness (Bloxham et al., 2016). This, in turn, could be fatal for the students in their forthcoming studies and carriers (O'Hagan \& Wigglesworth, 2015), as discrepancies in assessment might result in repeated revisions and a delay of graduation.

Karin Stolpe

karin.stolpe@liu.se

1 Department of Behavioural Sciences and Learning, Linköping University, Norrköping, Sweden

2 Department of Natural Science, Mathematics and Society, Malmö University, Malmö, Sweden

3 Department of Pedagogical, Curricular and Professional Studies, University of Gothenburg, Gothenburg, Sweden 
During the process of writing a thesis, students may have access to a supervisor. This means that they meet at least two different teachers: the supervisor and the examiner. Previous research indicate that teachers differ in terms of how they assess students' theses (e.g. Bloxham et al., 2016; O'Hagan \& Wigglesworth, 2015; Read et al., 2005; Gingerich et al., 2017). This leaves students frustrated, when they have followed the advice of their supervisor and later meet an examiner who assesses their work differently.

Assessing student theses is a highly complex and demanding activity (Shay, 2004). In the case of Swedish teacher education, the student thesis is the final degree work. The projects align with a professional perspective and are typically empirical (Erixon Arreman \& Erixon, 2017). In a sense, the student theses at the teacher education programmes are a balance act between the professional and academic discourse (Erixon Arreman \& Erixon, 2017; Arneback et al., 2017). However, despite the presence of the teaching profession, the academic orientation (Råde, 2019) in the Swedish student thesis tradition is strong. When the student thesis became mandatory in Swedish teacher education in 1993 (Ministry of Education and Research, 1993:100), the intention was to make the education more research based (Bergqvist, 2000), in order to strengthen the teaching profession. One objective was that students should develop independent and critical reasoning as well as a questioning attitude from writing a thesis (Bergqvist, 2000). Thus, the work to be assessed is complex, as it comprises both the process behind the actual theses and the production of a comprehensive text. The process resembles the research process in many senses. It consists of data collection, for example conducting interviews and observations or collecting textbook materials or curricula. The data are later analysed, and conclusions are drawn. The student needs to choose an appropriate method in order be able to carry out data collection, and a theoretical framework needs to be used to be able to perform the analysis. However, performing the process well is not enough to produce a good thesis. The student also must formulate a text that argues for the choices made, and that makes a clear, aligned argument from research question to conclusion. The text should make the process transparent. All these aspects, and probably more, can be considered when assessing student theses. Student thesis courses within teacher training programmes in Sweden often cover a period of 10 weeks (15 ECTP), and the thesis normally comprises approximately 30-40 pages.

One possible explanation for the differences observed between different assessors is that examiners originate from different academic disciplines and subject cultures (Becher, 1994). Within teacher education in particular, examiners from different subject areas and disciplinary traditions assess student theses. Examiners may have a background in pedagogy or behavioural studies, in pure disciplines such as maths, science or history, or in combinations like science education or social science education. It is fairly common for teachers who work in teacher education to have a teaching degree themselves, but this is not a prerequisite. Although there is a great variety in teacher educators' disciplinary backgrounds, Lundström et al. (2016) show that the variances between different academic disciplines are minor. This result is also supported by earlier research that found high inter-rater reliability between examiners from different disciplines (Kiley \& Mullins, 2004; BettanySaltikov et al., 2009). One explanation for why the studies show high inter-rater reliability is the way the criteria for assessment were expressed. Bettany-Saltikov et al. (2009) suggest that criteria that are generic in nature tend to lead to good inter-rater reliability. Hence, the criteria were formulated to the intended learning outcomes, such as "complexity of analysis" or "academic presentation of the work". Thereby, the idea was to formulate criteria that could be used to ensure fairness between institutions. 
In teacher education, lecturers from different disciplines are all part of the same teacher community. It is therefore possible to suggest that an assessment culture develops in such communities (Lave \& Wenger, 1991). Bloxham and Boyd (2012) have summarised two separate standards that exist among teachers in higher education: academic standards and private standards. The authors argue that assessors in the assessment process find themselves negotiating a potential tension between the two. The academic standards stand for the formal and measurable and are important for quality and external review. In contrast, the private standards represent teachers' tacit knowledge, and their "autonomous act of marking" (Bloxham \& Boyd, 2012). Furthermore, research indicates that new lecturers learn the implicit criteria and slowly harmonise their own personal criteria with the collective criteria of the department (Jawitz, 2009). These results indicate that another factor that could explain the differences between assessors is the experience of grading in a certain department or context.

Yet, another possible explanation for differences in assessment is the level of assessment experience. The level of experience may potentially play a role in terms of reliability. Research shows that experienced assessors tend to take a holistic approach rather than relying on formal criteria, in comparison with more novice assessors (Bloxham et al., 2011; Orr, 2010). Sadler (2009) describes the two ways of assessing, the holistic and the analytic approach, as being qualitative. Using the analytic approach, the examiner uses a list of formal criteria and makes the grading criterion by criterion. As a second step, the judgments are combined. In the holistic approach, a more global view is used to assess the student work. In this case, the assessor typically builds up a mental view gradually which leads to a judgment of the overall quality. These two approaches could be one explanation why assessors tend to differ in their decisions. However, these findings were not supported by Jansson et al. (2019). According to their findings, novices tend to lean on the formal criteria and use a more analytic approach in their assessment process. Experienced assessors lean on a holistic approach and use their personal as well as the formal criteria.

Although generic criteria may be one way to improve inter-rater reliability, as mentioned above (Bettany-Saltikov et al., 2009), some studies suggest that the use of assessment criteria per se may be a potential cause of variability (Bloxham et al., 2016). Bloxham et al. (2011) present criticism of the paradigm that assessment and grading should be guided by criteria, based on findings in the literature. Criteria could be interpreted, used and applied differently by teachers (Webster et al., 2000). However, some criteria, such as "structure" and "scientific quality", are more predictive for the final grade of theses (Haagsman et al., 2021). But, there are also assessors who do not use criteria, either because they do not agree with them or because they believe that their own judgments are sounder than the formal criteria (Baume et al., 2004). Added to this, assessors use personal criteria that are either explicit (Baume et al., 2004; Webster et al., 2000; Price, 2005) or implicit or tacit (Hunter \& Docherty, 2011).

Academic and disciplinary knowledge are often hidden or tacit (McGrath et al., 2019; Polanyi, 1966). McGrath et al. (2019) argue that there is a problem that teachers' knowledge of academic literacy is tacit. McGrath et al. (2019) wanted to increase the teachers' awareness and their metacognition to make them reflect on their knowledge and on how the academic literacy informs their teaching. Here, we assume that grading of complex tasks, for example student theses, is, at least to some extent, based on tacit knowledge. This assumption leads to methodological issues. 
When knowledge is tacit, it is hidden for the person him-/herself, and not possible to explicate. However, there are techniques to elucidate tacit knowledge, of which this study utilises two.

Previous research has tried to elucidate which personal criteria assessors use (e.g. Svennberg, 2017). However, this article takes a different approach and investigates how examiners rank different criteria for assessing student theses. In this sense, this study investigates the criteria examiners personally bring to the assessment process. These could be the examiners' own private standards, or the formal academic standards formulated as assessment guidelines (see Bloxham \& Boyd, 2012), or a mix thereof. In this article, the criteria stem from personal so-called constructs extracted from repertory grid interviews (Kelly, 1955) with lecturers (Björklund et al., 2016; Björklund, 2008). By using this approach, this article aims to add to insights into how assessors prioritise between different criteria for assessing student theses. Utilizing the Q methodology, where the constructs constitute the $\mathrm{Q}$ sample, we will be able to formulate different assessment profiles based on the relative ranking between different constructs. Moreover, we can seek explanations for the different assessment profiles among teacher trainers.

\section{Method}

To meet the aim of this study, Q methodology has been applied. Q methodology has been proposed as a method to capture complex phenomena that would be hard to grasp with other methods (Woods, 2012). Since assessment is a complex, holistic and experience-based activity, which also has a tacit dimension, this method could help scrutinise teacher trainers' condensed criteria for assessment. For a deeper discussion on the methods used in this study, see Björklund et al. (2016).

\section{Methodology}

Q methodology can be used to systematically study subjectivity, a person's opinions, beliefs, criteria, attitudes, etc. (Brown, 1993; Woods, 2012; Löfström et al., 2015). To form the Q sample, sixteen teacher educators from three different universities in Sweden were interviewed (see also Lundström et al., 2019). The interviews were conducted with the Repertory Grid Technique (RGT) (see Kelly, 1955; Zuber-Skerritt, 1987). The aim of using this technique is to elicit underlying, or tacit, criteria for assessment (Björklund, 2008). Hence, we used this technique to facilitate for the informants to verbalise their personal criteria. In preparation for the RGT interviews, the respondents had read between five and eight student theses. During the interviews, the respondents compared the theses in groups of three and were asked to say which one of the three deviated-positively or negatively-from the other two. During this first stage, the respondents did not have to provide grounds for their choices. In a second stage, the respondents were asked to describe noted differences, after which the respective respondent and the interviewer agreed on a label for these criteria. The criteria-or constructs (Kelly, 1955)-are referred to in this article as "statements". The goal of the RGT interviewing was to gather as many different statements as possible. 
The RGT interviews rendered a list of 92 different statements, which were later reduced to 45 statements (see Löfström et al., 2015). Here, our aims were to limit overlapping statements and to merge statements that were very similar. For example, "good method" and "insight in method" were combined into the statement "appropriate choice of method". In the same manner, "good literature" was merged with "relevant research literature", and "discussion about research ethics" was merged with "research ethics". The reduction was discussed by all four authors of this paper until consensus was reached. A complete list of statements was provided in Swedish and has been translated for this article (see Appendix Table 6).

The RGT interviews rendered a list of 92 different statements, which were later reduced to 45 statements (see Löfström et al., 2015). Here, our aim was to limit overlapping statements, and to merge statements that were very similar. For example, "good method" and "insight in method" were combined into the statement "appropriate choice of method". In the same manner, "good literature" was merged with "relevant research literature", and "discussion about research ethics" was merged with "research ethics". The reduction was discussed by all four authors of this paper until consensus was reached. A complete list of statements was provided in Swedish and have been translated for this article (see Appendix Table 6).

Data were collected using Q methodology (Watts \& Stenner, 2005). As a first step, respondents are presented with a selection of statements about a topic. These statements form the Q sample. Respondents are asked to rank the statements from their individual point of view, according to a preference or judgement about them, using quasi-normal distribution. The respondents then give their subjective opinions on the statements, thereby revealing their subjective viewpoints. These individual rankings (or viewpoints) are then subject to factor analysis. This factor analysis results in socalled "segments of subjectivity" (Brown, 1993), which in this article are referred to as "profiles". The method aims to discern existing patterns of thought (Zabala, 2014). One important step in Q methodology involves describing the character of these profiles. The number of informants is subordinate to the quality of the data. Brown (1993) argues that quality comes before quantity. To be able to define which features characterise the profiles, the most important thing is not having a large number of informants (Brown, 1993), but rather having a data sample that represents the communications of the topic.

Stephenson (1935) presented Q methodology as an inversion of conventional factor analysis in the sense that Q correlates people instead of tests. The correlation between personal profiles then indicates similar viewpoints, or segments of subjectivity (Brown, 1993). By correlating people, Q factor analysis provides information about similarities and differences in people's viewpoints. If each individual has his or her own specific likes and dislikes, Stephenson (1935) argued, their profiles will not correlate. However, if significant clusters of correlations exist, they can be factorised, or described as common viewpoints, and individuals can be measured with respect to them.

Stephenson (1935) made it clear that Q methodology refers to a population of $n$ different tests, each of which is measured or scaled by $m$ individuals. This means that the tests are given subjective scores by these individuals. Q sorting calls for a person to rank a set of stimuli according to an explicit rule, usually from agree $(+5)$ to disagree $(-5)$. The sorting is subjective in that the participant sorts the cards based on his or her own point of view. There is no right or wrong. 


\section{Data collection}

In the next step, a web-based Qsort was constructed and was distributed using the FlashQ software package created by Christian Hackert and Gernot Braehler (www.hackert.biz/ flashq). The Qsorts were stored in the cloud. The online tool FlashQ consisted of four different steps, which are briefly described below:

1. In the introduction, the participants were asked the following question: "What do you think is most important when describing a good student thesis?" To answer the question, the participants were presented to the different statements in random order. The participants were asked to read every statement and, using the drag-and-drop function with the mouse, place the statement in one of three boxes: less important to the left (1-pink), very important to the right (3-green) and the rest in the box in the middle (2-grey).

2. When all the criteria had been placed in one of the three boxes, the next step began. The participants were asked to place the criteria from the three boxes on a scale from 0 to 10 . There were restrictions on how many criteria could be assigned to each number on the scale (Fig. 1).

3. When all the criteria had been placed on the scale, the participants could make changes to the ranking.

4. In the last step, the participants were asked to provide some background information.

In the study presented in this article, the data collected via the online tool FlashQ have been analysed. The background questions in the fourth step provided information about

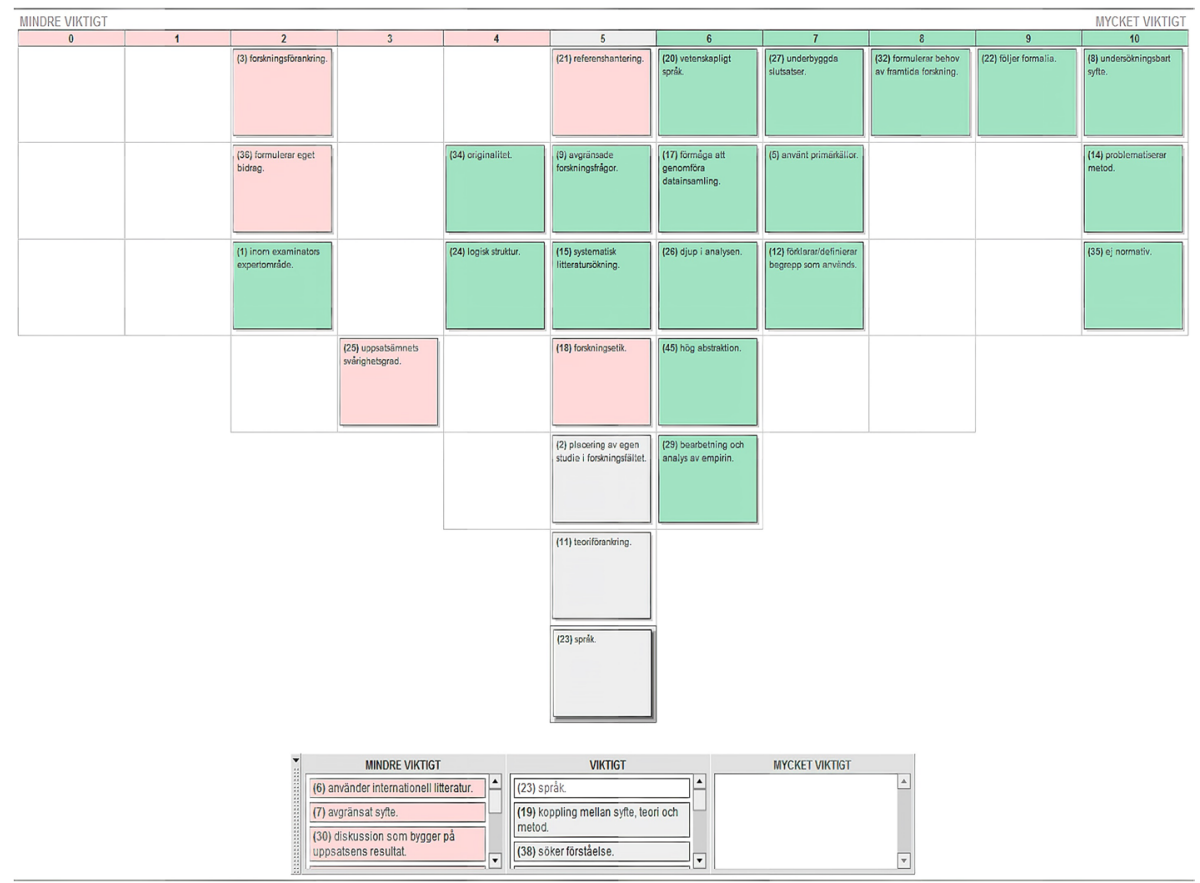

Fig. 1 The second step of the Qsort, which shows the restriction on each number on the axis. All statements are listed in Appendix Table 6 
how long the participants have been active as a supervisor or examiner of student theses, and approximately how many theses the informant has supervised or examined per year.

\section{Participants}

The online FlashQ was distributed as a link to a website in an invitation email explaining the purpose of the study. The vast majority of the participants worked at three different universities in Sweden. All three universities offer teacher training. The universities differ in terms of which formal criteria they officially use for assessment of student theses. An analysis of the fall-off shows that no variable such as gender, university or disciplinary background was overrepresented or underrepresented. The response rate was $36.9 \%$. Of the 66 participants, 36 were women and 30 were men.

All teachers who answered the survey were supervisors and/or examiners of student theses for teacher education. The sample was selected to ensure a distribution in terms of subject, experience and university. Sixty-one of the participants held $\mathrm{PhD}$ degrees, making them eligible to examine student theses. Five of the informants did not have $\mathrm{PhD}$ degrees and were only working as supervisors.

The study follows the ethical guidelines from the Swedish Research Council. The online FlashQ was anonymous, and no personal data were collected.

\section{Data analysis}

The data have been analysed using mixed methods (Ramlo \& Newman, 2011; Ramlo, 2016). Q methodology could be described as a way to seek for and describe patterns (Stenner \& Stainton Rogers, 2004). As a first step, data from the online FlashQ were saved in an Excel file and analysed in a software package: Ken-Q Analysis, A Web Application for Q Methodology (Banasick, 2019). Data were imported into the software package and processed. Five factors were extracted using the centroid method. Three significant factors were then rotated using the varimax method. These three factors explained $58 \%$ of the variation in the data. We chose to focus on the top and bottom six statements, calculated using the software package, since we wanted to describe the differences between the different factors (see, e.g. Table 1). As a second step, an interpretation was made to describe the three profiles as prototypical examiners by analysing distinguishing statements for each factor (see also Löfström et al., 2015). Moreover, the descriptions were also based on the analysis of the statements that differentiated the different factors. The descriptions were discussed by all four authors to ensure reliability.

\section{Findings}

The three extracted factors will be discussed in turn in an 'idealised' manner, describing a typical viewpoint of a subscriber to the factor. The interpretations are based on the given factor array and distinguishing statements for each factor as detailed in the KenQ output. 
Table 1 Factor A: top six most like/unlike statements

\begin{tabular}{lll}
\hline No. & Statement & Grid position \\
\hline 8 & Researchable purpose & +5 \\
24 & Logical structure & +5 \\
33 & Alignment & +5 \\
19 & Connection between purpose, theory, and method & +4 \\
27 & Substantiated conclusions & +4 \\
29 & Processing and analysis of empirical data & +4 \\
34 & Originality & -4 \\
32 & Formulating need for future research & -4 \\
25 & Difficulty of attempted content & -4 \\
39 & Gender perspective & -5 \\
1 & Within examiner's area of expertise & -5 \\
45 & High abstraction & -5 \\
\hline
\end{tabular}

\section{Factor A}

Factor A explains $22 \%$ of the variance. Fourteen participants had pure loadings on this factor. Table 1 highlights the six statements rated at each extreme, positive and negative (12 in total). These items will be referred to within the factor description.

Table 1 shows that factor A represents the belief that the alignment, structure and outline of the thesis are important. There should be a researchable purpose (8), the text structure should be logical (24), and there should be a connection between purpose, theory and method $(19,33)$.

Statements that were ranked high in factor A are characterised by considering wider perspectives on a thesis. Logical structure, connections between different parts (19), and alignment are all criteria that feature a holistic view of the thesis. The outline of the thesis is important for the participants placed within this factor. However, researchable purpose and processing and analysis of empirical data are statements which a majority of all informants rank high. These statements are not unique to factor $\mathrm{A}$ in that sense.

Statements which are lower ranked should not necessarily be seen as unimportant, since the scale is relative. However, they are not as important as those that were ranked high. It is hard to see any connections between the criteria which are ranked low within factor A. The lower ranked criteria could be inferred to deal less with the actual thesis as a product. High abstraction (45), originality (34) and difficulty of attempted content (25) are all statements that lie beyond the actual text. These statements say something about the author's ambition, rather than about the structure and precise content of the thesis. The statement within examiner's area of expertise (1) does not say anything about the quality of the thesis, but rather about the student's choice of subject compared to the examiner's research interests. Those statements ranked low by the informants in factor A are often also ranked low by other informants. This means that there are statements that a majority of the participants find less important in their assessment process.

Statements which distinguish factor A from other factors are listed in Table 2. All statements presented in the table are statements which differ significantly at either $p<0.01$ level or $p<0.05$ level. As mentioned above, structure is important for informants in factor A. However, we also note that some criteria distinguish factor 
Table 2 The statements that distinguish factor A from the other factors are significant at $p<0.05$. $*$ A distinguishing statement is significant at $p<0.01$

\begin{tabular}{lllll}
\hline No. & Statement & $\begin{array}{l}\text { Factor A grid } \\
\text { position }\end{array}$ & $\begin{array}{l}\text { Factor B grid } \\
\text { position }\end{array}$ & $\begin{array}{l}\text { Factor C grid } \\
\text { position }\end{array}$ \\
\hline 8 & Researchable purpose & $+5^{*}$ & +2 & +2 \\
24 & Logical structure & $+5^{*}$ & +1 & -1 \\
33 & Alignment & +5 & -1 & +3 \\
27 & Substantiated conclusions & +4 & +2 & +5 \\
44 & Text structure & $+3^{*}$ & 0 & -1 \\
18 & Research ethics & $+2^{*}$ & +5 & 0 \\
31 & Problematizing of results & $+1^{*}$ & +5 & +4 \\
10 & Interesting research question & +1 & -4 & 0 \\
38 & Quest for understanding & 0 & -4 & 2 \\
21 & Referencing & $0^{*}$ & +3 & -2 \\
14 & Problematizing method & $-1^{*}$ & +3 & +2 \\
41 & Exciting & $-2^{*}$ & -5 & -5 \\
37 & Discussing generalizability & $-3^{*}$ & 0 & 0 \\
42 & Strong narrative voice & $-3^{*}$ & -5 & -5 \\
45 & High abstraction & $-5^{*}$ & -3 & -4 \\
\hline
\end{tabular}

A from the other factors even though they are not classified as most important or unimportant. For example, referencing (21) and research ethics (18) are ranked high by informants in factor B and low by informants in factor C. The informants in factor A see them as neither important nor unimportant. Many of the statements ranked low by the informants in factor A differ significantly compared with the other factors. However, those statements are also ranked rather low by informants in factors $\mathrm{B}$ and $\mathrm{C}$.

Table 3 Factor B: top six most like/unlike statements

\begin{tabular}{lll}
\hline No. & Statement & $\begin{array}{l}\text { Factor } \\
\text { array } \\
\text { position }\end{array}$ \\
\hline 31 & Problematizing of results & +5 \\
18 & Research ethics & +5 \\
3 & Connections to research & +5 \\
23 & Use of language & +4 \\
28 & Answering research questions & +4 \\
19 & Connection between purpose, theory, and & +4 \\
34 & method & -4 \\
10 & Originality & -4 \\
38 & Interesting research question & -4 \\
1 & Quest for understanding & -5 \\
42 & Within examiner's area of expertise & -5 \\
41 & Strong narrative voice & -5 \\
\hline
\end{tabular}




\section{Factor B}

Factor B explains $20 \%$ of the variance. Seven participants had pure loadings on this factor. Table 3 highlights the six statements rated at each extreme (12 in total).

Factor B participants agree that a meta-perspective on the research process is important. This is revealed through the importance of problematizing (31). Through problematizing, the student makes strengths and weaknesses explicit in the thesis. Being able to do so calls for knowledge and awareness about the research process. Without this awareness, the student will not be able to problematise the results and the methods used. Also, answering research questions (28) is seen as critical in this factor, indicating that the research process is important.

Moreover, connection to research (3) indicates skills that characterise a welldeveloped research approach from the student. This statement, in line with the above-mentioned statements, includes an awareness of which choices are made. Also, the high ranking of the criteria research ethics (18) demonstrates that this factor regards areas where the student clarifies his or her considerations.

As seen in Table 3, statements of a more overarching character, such as interesting research question (10), originality (34) and exciting (41), are considered less important within this factor.

An overall interpretation of this factor is that it is characterised by stressing the research process rather than the actual thesis as a product. However, the process should be revealed in the thesis through problematizing and through connections to earlier research.

The statement researchable purpose (8) stands out for factor $\mathrm{B}$, compared with factors $\mathrm{A}$ and $\mathrm{C}$. Both factor $\mathrm{A}$ and factor $\mathrm{C}$ rank this statement very high, in contrast to factor B. In factor B, a researchable purpose is placed almost in the middle, which indicates that many statements are valued higher in factor B.

Table 4 Factor C: top six most like/unlike statements

\begin{tabular}{lll}
\hline No. & Statement & $\begin{array}{l}\text { Factor } \\
\text { array } \\
\text { position }\end{array}$ \\
\hline 27 & Substantiated conclusions & +5 \\
30 & Discussion based on the results of the student thesis & +5 \\
19 & Connection between purpose, theory, and method & +5 \\
29 & Processing and analysis of empirical data & +4 \\
28 & Answering research questions & +4 \\
31 & Problematizing of results & +4 \\
32 & Formulating need for future research & -4 \\
45 & High abstraction & -4 \\
39 & Gender perspective & -4 \\
34 & Originality & -5 \\
42 & Strong narrative voice & -5 \\
41 & Exciting & -5 \\
\hline
\end{tabular}




\section{Factor C}

Factor C explains $16 \%$ of the variance. Fifteen participants had pure loadings on this factor. Table 4 shows the six statements rated at each extreme (12 in total).

Factor $\mathrm{C}$ is represented by the belief that the content and research product are of importance. This is indicated by the high rating of the statements $s u b$ stantiated conclusion (27) and answering the research question (28). Also, the statement processing, and analysis of empirical data (29) indicates the importance of not just presenting raw data, but also analysing the data to some extent. Furthermore, the connection between purpose, theory, and method (19) is of importance to this group. One interpretation of this statement is that the product consists of an alignment between these three parts. If the purpose, theory and method do not match, it is not possible to draw any substantiated conclusions or answer the research questions. The suggestion that this profile focuses on the product is also indicated by the fact that the discussion should be based on the results of the thesis (30).

Compared with factor $\mathrm{A}$, factor $\mathrm{C}$ does not highlight the structure of the thesis explicitly (Table 2). For example, logical structure (24) and text structure (44) are both ranked relatively high in factor A compared with factor C. In line with this, the use of language (23) is ranked higher in both factor A and factor B compared with factor C. One statement that also separates factor $\mathrm{C}$ and factor $\mathrm{B}$ is research ethics, which is ranked much higher in factor B (18).

\section{Three main profiles}

As stated above, the findings of this study show that three different assessment profiles together explain $58 \%$ of the total variation in the data. A qualitative analysis of these different profiles implies three types of assessors.

The first profile, based on factor A, is characterised by highlighting statements relating to the outline of the thesis, where structure and language are important aspects. In this case, students should be able to write a coherent text with a logic that can be followed. This profile is characterised by statements that can be associated with emphasizing the text as a coherent and logical text. Factor A is named Logic text structure as product.

The second profile, based on factor B, takes a meta-perspective on the thesis, and stresses the importance of taking a conscious approach to the research process. For this group, it is important to problematise the different choices made during the process, such as research ethics and the results. Factor B is labelled Research process as product.

Factor $\mathrm{C}$ is the basis for the third profile which shows a clear favour for statements relating to the results of the research process. In this profile, it is important to obtain a result that can answer the research questions and that is aligned with the theory and method used. The text itself is not the most important thing for this group, but rather the results presented in the text. Factor $\mathrm{C}$ is called Results as product.

So far, the differences between the three factors have been emphasised. However, there are also statements that unite the three factors (Table 5). Since some of them are 
Table 5 Statements that are ranked high by all three factors

\begin{tabular}{lllll}
\hline No. & Statement & Factor 1 & Factor 2 & Factor 3 \\
\hline 28 & Answering research questions & +3 & +3 & +4 \\
4 & Use of relevant research literature & +3 & +3 & +3 \\
19 & $\begin{array}{l}\text { Connection between purpose, } \\
\text { theory, and method }\end{array}$ & +4 & +5 & +4 \\
\hline
\end{tabular}

not ranked high by any of the groups, such as use of relevant research literature (4), they do not appear in the tables above. The statement connection between purpose, theory, and method (19) is equally ranked within the three factors. This means that even if there are differences in terms of which statements are emphasised, there are also statements that unite them.

\section{Discussion}

This study aims to expand our understanding of how different assessors prioritise between constructs for assessment. This research investigates the criteria that examiners bring to the assessment process, and this could be a combination of personal and institutional criteria. The constructs that comprise the Q-sample, originated from interviews in which assessors were asked to distinguish different theses from each other (Repertory grid technique, see Kelly, 1955). Using this approach, we were able to elucidate constructs that were personal to the assessors. We argue that this may take us one step closer to the actual process of how the decision process is performed. Research shows the difficulties of using specific criteria for assessment (Bloxham et al., 2011, 2016). In this study, we take another point of departure and seek to elucidate qualitatively divergent assessment profiles amongst teacher trainers who assess student theses from teacher education programmes in Sweden.

The results show three qualitatively different assessment profiles, which together explain $58 \%$ of the total variation in the data. The first profile, which we have named Logic text structure as product, highlights the importance of a coherent and well-structured text. We refer to the second profile, which takes a meta-perspective on the overall work with a thesis, as Research process as product. Different choices made during the process, such as a problematization of the results or a discussion on research ethics, are important to this profile. The third profile has been labelled Results as product due to the high importance of a result that is in line with the research questions and the theory and method. One should keep in mind that there is no hierarchical order between these different profiles. In the following, we will discuss each of these profiles separately before providing some concluding remarks and implications for assessment.

To be able to create a thesis which shows logic of the text structure, the student needs to have a clear purpose. The logic text structure is required to be able to present the analysis of empirical data. We would argue that an examiner who falls into this category does not look at details, but rather at the bigger picture. This could be compared with earlier research stating that experienced assessors tend to take a holistic approach rather than relying on formal criteria (Bloxham 
et al., 2011; Orr, 2010). Drawing on this conclusion, it would be possible to suggest that examiners with the profile Logic text structure as product have more experience of reading and assessing student theses in teacher education. However, this is not revealed in our data and is something that should be further investigated.

The criteria ranked lowest in this factor-originality, high abstraction, and difficulty-might not be considered as criteria to decide whether a thesis should pass. Instead, these statements can be used to decide whether a thesis should receive a higher grade than simply a pass. This means that lower ranked factors should not be seen as unimportant. Instead, these factors should be inferred as less important than the others.

Within the factor Research process as product, the process of the thesis is seen as important. Meanwhile, it is important for this factor that the author of the text is transparent about the process. This implies that the thesis shows that the student is aware of which constraints and benefits a certain method entails. This approach also shows the complexity of assessing student theses. A thesis demonstrates the ability to both perform research work and write a coherent report that argues for the choices made. In the case of Research process as product, the research process dominates over the product, and hence requires a meta-perspective in the text.

The last factor, Results as product, takes a perspective that distances the written product from the research process. This is indicated by the stronger emphasis on statements relating to the results of the research process. In this factor, it seems important that the product of a student thesis is a result from a research process and the text appears to be subordinated.

Even though the results show three distinct assessment profiles, it should be kept in mind that these explain about half (58\%) of the research data. This indicates that there are combinations of these three profiles among the informants of this study. Moreover, the results show that there are some criteria that are equally ranked between the different profiles (Table 5). Said criteria are important, in that they are relevant to research per se. To give answers to the research questions, use relevant research literature, and expose a connection between purpose, theory and method are all important to characterise research. Examiners with background in research could be expected to share a common ground related to this experience. Hence, this should influence their personal criteria for assessing student theses that share many properties with research.

This study adds novel knowledge on the criteria teacher trainers bring to the assessment process. Earlier research have shown that examiners use an holistic approach, rather than formal criteria in their marking (Bloxham et al., 2011). However, in this study, we are able to distinguish different profiles and hence show that the holistic approach could have different foci. Jansson et al. (2019) show that novice teachers are not more often stuck in detail when marking, than do expert teachers. Even so, novice teachers tend to formulate their judgements more closely to formulations in the formal criteria. Moreover, Bloxham and Boyd (2012) have formulated two sets of standards: academic and private standards. In our study, we do not separate between these two. Rather, we take the approach to look how examiners prioritise between different criteria. Our findings thus imply that all profiles are a mix of both personal and institutional criteria. Hence, the differences in examiners' assessment could be explained by the fact that their priorities differ.

Moreover, this study provides methodological insights in how different methods can be combined to elucidate knowledge that is tacit or at least hard to put in words. 
The combination of Repertory Grid Technique and Q methodology reveal new knowledge on higher education teachers' assessment priorities.

\section{Concluding remarks and implications}

We suggest that knowledge about the three profiles that we present in this study could help inform the discussion on how more reliable formal criteria can be formulated. As previous research have suggested, more generic criteria seem to give a higher inter-rater reliability (Bettany-Saltikov et al., 2009; Haagsman et al., 2021). However, this may not be enough. We suggest that examiners and supervisors should discuss how they prioritise between different criteria. The three different profiles could be used as a starting point for such discussion. Furthermore, the outcome of such discussions could also be made explicit for the students so that they are aware of what they are aiming for.

The participants in this study work at three different universities with different formal criteria for assessing student theses. They also have different disciplinary backgrounds, and their experiences of assessment vary. Despite this, three different profiles emerged from the data, which were not correlated to university, gender, or level of experience. This result indicates that factors other than the formal criteria seem to inform the examiners regarding how to sort the criteria based on importance. Moreover, another study based on the same data set, Lundström et al. (2019) show that there is no correlation between background variables such as university, disciplinary background or gender and the preference for different criteria.

This study proposes an explanation to why students may feel squeezed between different preferences of the supervisor and the examiner. In the examination process, a student may meet an examiner that emphasises the logic of the text structure. On the surface, both the supervisor and the examiner might follow the same formal criteria, but as they give emphasis to different criteria, and add personal criteria, the situation for the student is as for the best confusing. It could lead to many rounds of revisions. In the worst case this could even prevent the student from graduating. As earlier research suggests, students' sense of a fair assessment is associated with methods that are learner-centred (Flores et al., 2015). That is, methods such as portfolios and projects that develop student autonomy and sense of responsibility. However, since assessment of student theses are limited by norms and guidelines, both formal and personal, the assessment process could be characterised as traditional. From a student point of view, it is hard to grasp the demands and expectations. This may leave the student with a feeling that the assessment does not reward effort, but rather measures 'luck'. According to Sambell et al. (1997), these permissions will potentially leave the student with a feeling of unfairness.

One limitation of this study is that it does not lean on examiners' actual assessment process. Using different methods and methodologies, we have sought to elucidate which criteria examiners find the most important. More research is needed to know if the assessment process is informed by these criteria and if it is possible to find the profiles in this process.

The results from this study indicate that a more thorough discussion about what should be the focus when assessing student theses. This study suggests a lack of coherence about whether it should be the process, the product, or the logic of the text (or something else) that should be the main focus of the assessment. We would argue that this contradiction could lead to the same student thesis ending up with different marks, depending on what the examiner finds most important. This is an area which needs further investigation. 


\section{Appendix}

Table 6 A list of the 45 statements that constituted the Q sample

\begin{tabular}{|c|c|}
\hline No. & Statement \\
\hline 1 & Within examiner's area of expertise \\
\hline 2 & Positioning the study in the research field \\
\hline 3 & Connections to research \\
\hline 4 & Use of relevant research literature \\
\hline 5 & Use of primary references \\
\hline 6 & Use of international literature \\
\hline 7 & Defined aim \\
\hline 8 & Researchable purpose \\
\hline 9 & Defined research questions \\
\hline 10 & Interesting research question \\
\hline 11 & Connection to theory \\
\hline 12 & Explaining/defining concepts that are used \\
\hline 13 & Appropriate choice of method \\
\hline 14 & Problematizing method \\
\hline 15 & Systematic search for literature \\
\hline 16 & Transparent description of method \\
\hline 17 & Ability to perform data collection \\
\hline 18 & Research ethics \\
\hline 19 & Connection between purpose, theory, and method \\
\hline 20 & Scientific language \\
\hline 21 & Referencing \\
\hline 22 & Following formalities \\
\hline 23 & Use of language \\
\hline 24 & Logical structure \\
\hline 25 & Difficulty of attempted content \\
\hline 26 & Analysis with depth \\
\hline 27 & Substantiated conclusions \\
\hline 28 & Answering research questions \\
\hline 29 & Processing and analysis of empirical data \\
\hline 30 & Discussion based on the results of the student thesis \\
\hline 31 & Problematizing of results \\
\hline 32 & Formulating need for future research \\
\hline 33 & Alignment \\
\hline 34 & Originality \\
\hline 35 & Not normative \\
\hline 36 & Phrasing own research contribution \\
\hline 37 & Discussing generalisability \\
\hline 38 & Quest for understanding \\
\hline 39 & Gender perspective \\
\hline 40 & Relevant for profession \\
\hline 41 & Exciting \\
\hline 42 & Strong narrative voice \\
\hline 43 & Oral defence of thesis \\
\hline 44 & Text structure \\
\hline 45 & High abstraction \\
\hline
\end{tabular}


Funding Open access funding provided by Linköping University. This project has been funded by the Swedish Research Council.

\section{Declarations}

Conflicts of interest The authors declare that they have no conflict of interest.

Open Access This article is licensed under a Creative Commons Attribution 4.0 International License, which permits use, sharing, adaptation, distribution and reproduction in any medium or format, as long as you give appropriate credit to the original author(s) and the source, provide a link to the Creative Commons licence, and indicate if changes were made. The images or other third party material in this article are included in the article's Creative Commons licence, unless indicated otherwise in a credit line to the material. If material is not included in the article's Creative Commons licence and your intended use is not permitted by statutory regulation or exceeds the permitted use, you will need to obtain permission directly from the copyright holder. To view a copy of this licence, visit http://creativecommons.org/licenses/by/4.0/.

\section{References}

Arneback, E., Englund, T., \& Solbrekke, T. D. (2017). Achieving a professional identity through writing. Education Inquiry, 8(4), 284-298.

Banasick, S. (2019). Ken-Q analysis, a web application for Q methodology, version 1.0.6. Retrieved March 15, 2020, from https://shawnbanasick.github.io/ken-q-analysis.

Baume, D., Yorke, M., \& Coffey, M. (2004). What is happening when we assess, and how can we use our understanding of this to improve assessment? Assessment \& Evaluation in Higher Education, 29(4), 451-477.

Becher, T. (1994). The significance of disciplinary differences. Studies in Higher Education, 19(2), $151-162$.

Bergqvist, K. (2000). Examensarbetet. Ett bidrag till vetenskaplighet i lärarutbildningen? [Student thesis. A contribution to the research base in teacher education?]. Pedagogisk forskning $i$ Sverige, 5(1), 1-18.

Bettany-Saltikov, J., Kilinc, S., \& Stow, K. (2009). Bones, boys, bombs and booze: An exploratory study of the reliability of marking dissertations across disciplines. Assessment \& Evaluation in Higher Education, 34(6), 621-639.

Björklund, L. (2008). The Repertory Grid Technique: Making tacit knowledge explicit: Assessing creative work and problem solving skills. In H. Middleton (Ed.), Researching technology education: Methods and techniques (pp. 46-69). Brill Sense.

Björklund, L., Stolpe, K., \& Lundström, M. (2016). Making tacit knowledge explicit. Three methods to assess attitudes and believes. In J. Lavonen, K. Juuti, A. Lampiselkä, A. Uitto, \& K. Hahl (Eds.), Science Education Research: Engaging Learners for a Sustainable Future: Proceedings of ESERA 2015, Helsinki, Finland, 2016 (Vol. 11, pp. 1733-1741): University of Helsinki.

Bloxham, S., \& Boyd, P. (2012). Accountability in grading student work: Securing academic standards in a twenty-first century quality assurance context. British Educational Research Journal, 38(4), 615-634.

Bloxham, S., Boyd, P., \& Orr, S. (2011). Mark my words: The role of assessment criteria in UK higher education grading practices. Studies in Higher Education, 36(6), 655-670.

Bloxham, S., den-Outer, B., Hudson, J., \& Price, M. (2016). Let's stop the pretence of consistent marking: Exploring the multiple limitations of assessment criteria. Assessment \& Evaluation in Higher Education, 41(3), 466-481. https://doi.org/10.1080/02602938.2015.1024607.

Brown, S. R. (1993). A primer on Q methodology. Operant Subjectivity, 16(3/4), 91-138.

Erixon Arreman, I., \& Erixon, P. O. (2017). Professional and academic discourse-Swedish student teachers' final degree project in Early Childhood Education and Care. Linguistics and Education, 37, 52-62.

Flores, M. A., Veiga Simão, A. M., Barros, A., \& Pereira, D. (2015). Perceptions of effectiveness, fairness and feedback of assessment methods: A study in higher education. Studies in Higher Education, 40(9), 1523-1534. https://doi.org/10.1080/03075079.2014.881348.

Gingerich, A., Ramlo, S. E., van der Vleuten, C. P., Eva, K. W., \& Regehr, G. (2017). Inter-rater variability as mutual disagreement: Identifying raters' divergent points of view. Advances in Health Sciences Education, 22(4), 819-838. 
Haagsman, M., Snoek, B., Peeters, A., Scager, K., Prins, F., \& van Zanten, M. (2021). Examiners' use of rubric criteria for grading bachelor theses. Assessment \& Evaluation in Higher Education, 1-15. https://doi.org/10.1080/02602938.2020.1864287.

Hunter, K., \& Docherty, P. (2011). Reducing variation in the assessment of student writing. Assessment \& Evaluation in Higher Education, 36(1), 109-124.

Jansson, M., Carle, J., Gunnarsson, A., \& Ekbrand, H. (2019). How experience affects assessment-a longitudinal study of assessment of university students' essays. Studies in Higher Education, 44(4), $719-732$.

Jawitz, J. (2009). Learning in the academic workplace: The harmonization of the collective and the individual habitus. Studies in Higher Education, 34(6), 601-614.

Kelly, G. A. (1955). The Psychology of Personal Constructs. Routledge.

Kiley, M., \& Mullins, G. (2004). Examining the examiners: How inexperienced examiners approach the assessment of research theses. International Journal of Educational Research, 41, 121-135.

Lave, J., \& Wenger, E. (1991). Situated learning: Legitimate peripheral participation. Cambridge University Press.

Lundström, M., Björklund, L., Stolpe, K., \& Åström, M. (2016). Assessing student theses: Differences and similarities between examiners from different academic disciplines. Practitioner Research in Higher Education, 10(1), 217-226.

Lundström, M., Stolpe, K., Björklund, L., \& Åström, M. (2019). Konsumtionsuppsatser som ny bedömningspraktik för lärarutbildare [Systematic reviews as new assessment practice for teacher educators]. Pedagogisk forskning i Sverige, 24(1), 25-45.

Löfström, E., Trotman, T., Furnari, M., \& Shephard, K. (2015). Who teaches academic integrity and how do they teach it? Higher Education, 69(3), 435-448. https://doi.org/10.1007/ s10734-014-9784-3.

McGrath, L., Negretti, R., \& Nicholls, K. (2019). Hidden expectations: Scaffolding subject specialists' genre knowledge of the assignments they set. Higher Education, 78(5), 835-853. https://doi.org/10. 1007/s10734-019-00373-9.

Ministry of Education and Research (1993:100). Högskoleförordningen. Retrieved Mars 10, 2020, from https://www.riksdagen.se/sv/Dokument-Lagar/Lagar/Svenskforfattningssamling/Hogskoleforordning1993100_sfs-1993-100/.

O’Hagan, S. R., \& Wigglesworth, G. (2015). Who's marking my essay? The assessment of non-nativespeaker and native-speaker undergraduate essays in an Australian higher education context. Studies in Higher Education, 40(9), 1729-1747.

Orr, S. (2010). 'We kind of try to merge our own experience with the objectivity of the criteria': The role of connoisseurship and tacit practice in undergraduate fine art assessment. Art, Design \& Communication in Higher Education, 9(1), 5-19.

Polanyi, M. (1966). The Tacit Dimension. Doubleday \& Company Inc.

Price, M. (2005). Assessment standards: The role of communities of practice and the scholarship of assessment. Assessment \& Evaluation in Higher Education, 30(3), 215-230.

Ramlo, S. (2016). Mixed method lessons learned from 80 years of Q methodology. Journal of Mixed Methods Research, 10(1), 28-45.

Ramlo, S., \& Newman, I. (2011). Q methodology and its position in the mixed methods continuum. Operant Subjectivity, 34(3), 172-191.

Read, B., Francis, B., \& Robson, J. (2005). Gender, 'bias', assessment and feedback: Analyzing the written assessment of undergraduate history essays. Assessment \& Evaluation in Higher Education, 30(3), 241-260.

Råde, A. (2019). Professional formation and the final thesis in European teacher education: A fusion of academic and professional orientation. Education Inquiry, 10(3), 226-242.

Sadler, D. R. (2009). Indeterminacy in the use of preset criteria for assessment and grading. Assessment \& Evaluation in Higher Education, 34(2), 159-179.

Sambell, K., McDowell, L., \& Brown, S. (1997). "But is it fair?": An exploratory study of student perceptions of the consequential validity of assessment. Studies in Educational Evaluation, 23(4), $349-371$.

Shay, S. B. (2004). The assessment of complex performance: A socially situated interpretative act. Harvard Educational Review, 74(3), 307-329.

Stenner, P., \& Stainton Rogers, R. (2004). Q methodology and qualiquantology: The example of discriminating between emotions. In Z. Todd, B. Nerlich, S. McKeown, \& D. D. Clarke (Eds.), Mixing methods in psychology: The integration of qualitative and quantitative methods in theory and practice. Psychology Press.

Stephenson, W. (1935). Correlating persons instead of tests. Character and Personality, 4, 17-24. 
Svennberg, L. (2017). Swedish PE teachers' understandings of legitimate movement in a criterion-referenced grading system. Physical Education and Sport Pedagogy, 22(3), 257-269.

Watts, S., \& Stenner, P. (2005). Doing Q methodology: Theory, method and interpretation. Qualitative Research in Psychology, 2(1), 67-91.

Webster, F., Pepper, D., \& Jenkins, A. (2000). Assessing the undergraduate dissertation. Assessment \& Evaluation in Higher Education, 25(1), 71-80.

Woods, C. (2012). Exploring emotion in the higher education workplace: Capturing contrasting perspectives using Q methodology. Higher Education, 64(6), 891-909. https://doi.org/10.1007/s10734-012-9535-2.

Zabala, A. (2014). qmethod: A package to explore human perspectives using Q methodology. The R Journal, 6(2), 163-173.

Zuber-Skerritt, O. (1987). A repertory grid study of staff and students' personal constructs of educational research. Higher Education, 16(5), 603-623.

Publisher's note Springer Nature remains neutral with regard to jurisdictional claims in published maps and institutional affiliations. 